\title{
Efficacy of continuous erythropoietin receptor activator for end-stage renal disease patients with renal anemia before and after peritoneal dialysis initiation
}

\author{
Daisuke Fujimoto ${ }^{1} \cdot$ Masataka Adachi $^{1}{ }^{\circledR} \cdot$ Yoshikazu Miyasato $^{1} \cdot$ Yusuke Hata ${ }^{1} \cdot$ Hideki Inoue $^{1} \cdot$ Akira Oda $^{1}$. \\ Yutaka Kakizoe ${ }^{1} \cdot$ Terumasa Nakagawa $^{1}$ - Akiko Shimasaki ${ }^{1} \cdot$ Keishi Nakamura $^{1} \cdot$ Yu Nagayoshi $^{1}$. \\ Masashi Mukoyama'
}

Received: 5 March 2020 / Accepted: 15 September 2020 / Published online: 6 October 2020

(c) The Author(s) 2020

\begin{abstract}
Background Serial management of renal anemia using continuous erythropoietin receptor activator (CERA) throughout the peritoneal dialysis initiation period has rarely been reported. We investigated the efficacy and dosage of CERA treatment from pre- to post-peritoneal dialysis initiation for anemia management in patients with end-stage renal disease.

Methods Twenty-six patients (13 men; mean age 60.9 years) who started peritoneal dialysis between April 2012 and April 2018 were investigated. Serial changes in hemoglobin levels, transferrin saturation and ferritin levels, CERA dosage, and the erythropoietin resistance index (ERI) over a 48 week period were retrospectively examined.

Results Mean hemoglobin levels increased significantly from $10.5 \mathrm{~g} / \mathrm{dL}$ at 24 weeks prior to the peritoneal dialysis initiation to $11.5 \mathrm{~g} / \mathrm{dL}$ at 4 weeks post-initiation. The proportion of patients with hemoglobin levels $\geq 11 \mathrm{~g} / \mathrm{dL}$ increased significantly after peritoneal dialysis initiation. The mean CERA dosage was $57.0 \mu \mathrm{g} / \mathrm{month}$ at 24 weeks prior to dialysis initiation, $86.5 \mu \mathrm{g} / \mathrm{month}$ at initiation, and $72.0 \mu \mathrm{g} / \mathrm{month}$ at 4 weeks post-initiation. Thus, the dosage tended to increase immediately before peritoneal dialysis initiation and then decreased thereafter. Hemoglobin levels were significantly lower, while the CERA dosage for maintaining hemoglobin levels and ERI tended to be higher at dialysis initiation in patients with diabetes than in those without diabetes.

Conclusion Treatment with CERA prior to and during the peritoneal dialysis initiation achieved fairly good anemia management in patients with and without diabetes. The CERA dosage could be reduced in patients without diabetes after dialysis initiation.
\end{abstract}

Keywords Continuous erythropoietin receptor activator (CERA) - Diabetes mellitus · Erythropoietin resistance index (ERI) $\cdot$ Peritoneal dialysis $\cdot$ Renal anemia

\section{Introduction}

Electronic supplementary material The online version of this article (https://doi.org/10.1007/s10157-020-01973-x) contains supplementary material, which is available to authorized users.

Masataka Adachi

m-adachi@gpo.kumamoto-u.ac.jp

1 Department of Nephrology, Kumamoto University Graduate School of Medical Sciences, 1-1-1 Honjo, Chuo-ku, Kumamoto 860-8556, Japan
Anemia is an almost inevitable complication of end-stage renal disease (ESRD) due to the inadequate production of endogenous erythropoietin by the impaired kidneys [1]. Renal anemia is significantly associated with cardiovascular events and all-cause mortality [2,3]. Erythropoiesis-stimulating agents (ESAs) improve not only renal anemia but also the related clinical outcomes, including better quality of life (QOL) [4], longer kidney survival [5, 6], and slower progression of left ventricular hypertrophy $(\mathrm{LVH})$ in patients with chronic kidney disease (CKD) [7, 8]. Current guidelines recommend a target hemoglobin $(\mathrm{Hb})$ level of 10.0-12.0 g/ 
$\mathrm{dL}$ for dialysis and 10.0-13.0 g/dL for non-dialysis CKD patients [9-11].

Continuous erythropoietin receptor activator (CERA) is a chemically synthesized ESA that differs from epoetin beta through the integration of an amide bond between an amino group of epoetin beta and a specific, linear methoxy-polyethylene glycol polymer chain [12]. When administered intravenously or subcutaneously, CERA exhibits a long half-life (approximately $130 \mathrm{~h}$ ) and low clearance; these characteristics, together with its unique receptor-binding properties, feature a novel pharmacological profile different from that of other ESAs currently used [12-14].

To date, many studies on the treatment for renal anemia using ESAs have been reported in peritoneal dialysis (PD) patients before and after dialysis initiation [14-16]. However, there have been few reports on the serial management of renal anemia using CERA throughout the period from pre- to post-PD initiation. Furthermore, it has been shown that patients with diabetic kidney disease, a major cause of ESRD, develop renal anemia earlier than those with other types of renal diseases [17], but information about the comparison of anemia management during a PD initiation period is scarce.

Therefore, we here investigated the usefulness of CERA for anemia management in PD patients, to examine its efficacy and dosage before and after PD initiation. We also investigated the impact of the presence of diabetes on anemia control in PD patients, with a view to evaluating the treatment efficacy of CERA.

\section{Subjects and methods}

\section{Participants and study design}

Data from 26 patients with ESRD, who were older than 18 years and who started PD between April 2012 and April 2018 at Kumamoto University Hospital, Japan, were analyzed in this study. Patients were receiving maintenance continuous ambulatory peritoneal dialysis (CAPD), tidal peritoneal dialysis (TPD), or nightly peritoneal dialysis (NPD). Exclusion criteria were as follows: (1) treatment with recombinant human erythropoietin or ESAs other than CERA, (2) blood transfusion therapy during the observational period, and (3) known malignancies (Fig. 1).

This study was a retrospective, single-center observational survey, performed using an opt-out method of enrolment at Kumamoto University Hospital.

\section{Laboratory measurements and data collection}

The serum for determination of biochemical parameters was obtained from each patient at regular outpatient visits.

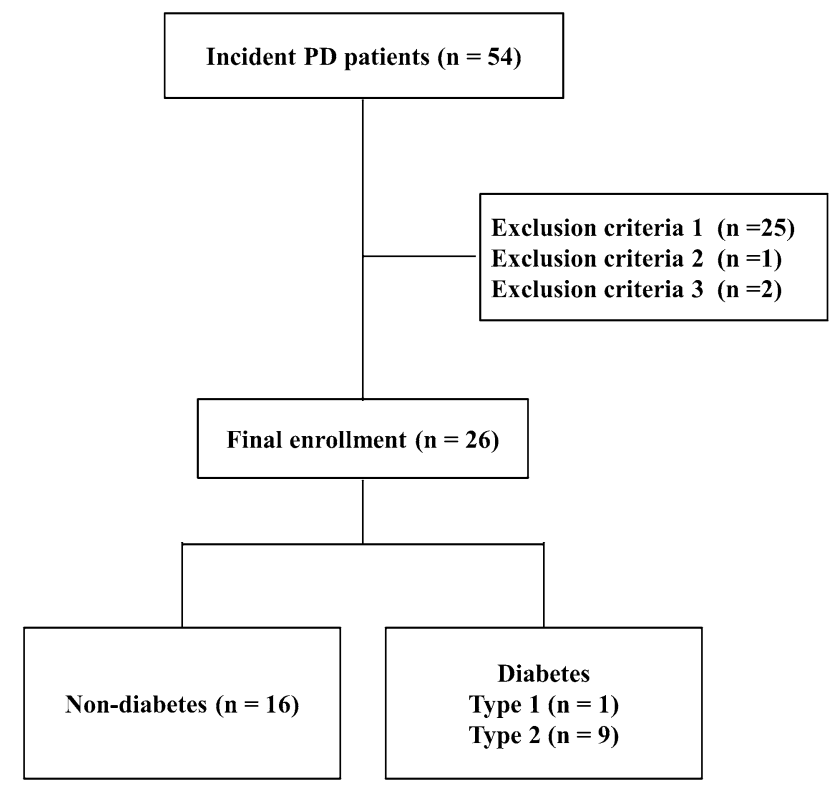

Fig. 1 A flow-chart showing the screening and enrollment of the patients

$\mathrm{Hb}$ levels, iron parameters [transferrin saturation (TSAT) and ferritin], serum albumin (Alb), serum creatinine (Cr), C-reactive protein (CRP), and intact parathyroid hormone (iPTH) levels were determined once a month at SRL, Inc. (Tokyo, Japan).

The estimated glomerular filtration rate (eGFR) of each participant was calculated using the following formula [18]:

$$
\begin{aligned}
& \mathrm{eGFR}\left(\mathrm{mL} / \mathrm{min} / 1.73 \mathrm{~m}^{2}\right) \\
& =194 \times \text { serum creatinine } \\
& \times \text { age }^{-0.287} \times 0.739(\text { if female })
\end{aligned}
$$

iPTH was measured by chemiluminescent immunoassay. Baseline demographic and clinical characteristics, including age, sex, body weight, co-morbidities, laboratory data, cardiothoracic ratio, and iron preparation use were recorded.

\section{Assessments}

$\mathrm{Hb}$ levels, iron parameters, CERA dosage, and erythropoietin resistance index (ERI) [CERA amount $(\mu \mathrm{g}) /$ body weight $(\mathrm{kg}) / \mathrm{Hb}(\mathrm{g} / \mathrm{dL}) / 4$ weeks] were monitored retrospectively over a period of 48 weeks, from 24 weeks before to 24 weeks after PD initiation. We also compared the differences in these parameters between patients with and without diabetes (10 and 16 patients, respectively). 


\section{Statistical analyses}

Statistical analyses were performed using JMP statistical discovery software, version 11.0 (SAS Institute Inc., Cary, $\mathrm{NC}$, USA) for Windows. Data are expressed as mean $\pm \mathrm{SD}$ for normally distributed (parametric) continuous variables.

For efficacy analyses, we compared the mean change in $\mathrm{Hb}$ level, CERA dosage, iron parameters, and ERI between the baseline and other time-points for patients who received CERA, using a one-way analysis of variance. McNemar's test was used to calculate the changes in $\mathrm{Hb}$ level categories (Hb levels $\geq$ or $<11 \mathrm{~g} / \mathrm{dL}$ ) before and after PD initiation. Comparisons between patients with and without diabetes were performed using Welch's $t$ test. $P<0.05$ was considered statistically significant.

\section{Results}

Table 1 shows the baseline demographic and laboratory data of the patients enrolled at the initiation of PD therapy. Thirteen men and 13 women with a mean age of $60.9 \pm 11.7$ years were included. All patients received adequate dialysis treatment. The most common cause of ESRD was diabetic kidney disease (38.4\%), followed by IgA nephropathy (26.9\%), and hypertensive nephrosclerosis (11.5\%). Mean Hb levels were $10.1 \pm 1.1 \mathrm{~g} / \mathrm{dL}$; TSAT and serum ferritin levels were adequately controlled (TSAT $25.2 \pm 8.3 \%$, ferritin $146.1 \pm 134.1 \mathrm{ng} / \mathrm{mL}$ ). There were no active infectious diseases, severe heart failure, or gastrointestinal bleeding during the evaluation period. The percentage of patients receiving iron replacement therapy was $11.5 \%$. Renin-angiotensin system (RAS) inhibitors [angiotensinconverting-enzyme inhibitor (ACEI) and angiotensin II receptor blocker (ARB)] were administered to $19(73.1 \%)$ patients at PD initiation. $\mathrm{Hb}$ levels between groups with or without RAS inhibitors were not significantly different [average $\mathrm{Hb}$ level $10.1 \mathrm{~g} / \mathrm{dL}$ (with RAS inhibitor) vs. $9.8 \mathrm{~g}$ / $\mathrm{dL}$ (without RAS inhibitor), $P=0.252$ ]. No adverse events were observed during this study.

The PD therapy varied. Nineteen patients were treated using CAPD, 3 patients were treated by TPD, and 4 patients by NPD.

The mean $\mathrm{Hb}$ levels were $10.5 \mathrm{~g} / \mathrm{dL}$ at 24 weeks prior to PD initiation, $10.1 \mathrm{~g} / \mathrm{dL}$ at PD initiation, and $11.5 \mathrm{~g} / \mathrm{dL}$ at 4 weeks after initiation (Fig. 2). Thus, time-dependent changes revealed that $\mathrm{Hb}$ levels tended to decrease as PD initiation approached, reached their lowest levels at the time of PD initiation, and significantly increased after PD initiation (at weeks 4, 8, and 12 after initiation) (Fig. 2). Throughout this period, the average $\mathrm{Hb}$ levels rarely fell below $10 \mathrm{~g} / \mathrm{dL}$. The mean CERA dosage was $57.0 \mu \mathrm{g} /$ month at 24 weeks
Table 1 Baseline demographics and clinical characteristics of the patients

\begin{tabular}{ll}
\hline Patient number & 26 (male/female $=13 / 13)$ \\
Age (years) & $60.9 \pm 11.7$ \\
Body weight $(\mathrm{kg})$ & $60.8 \pm 9.9$ \\
Cause of CKD, $n(\%)$ & \\
Diabetic kidney disease & $10(38.4)$ \\
IgA nephropathy & $7(26.9)$ \\
Hypertensive nephrosclerosis & $3(11.5)$ \\
ADPKD & $1(3.8)$ \\
FSGS & $1(3.8)$ \\
Lupus nephritis & $1(3.8)$ \\
Others (or unknown) & $3(11.5)$ \\
BUN (mg/dL) & $74.7 \pm 25.1$ \\
Serum Cr (mg/dL) & $9.47 \pm 1.90$ \\
eGFR (mL/min/1.73 m $\left.{ }^{2}\right)$ & $4.65 \pm 1.35$ \\
Hb $(\mathrm{g} / \mathrm{dL})$ & $10.1 \pm 1.1$ \\
TSAT $(\%)$ & $25.2 \pm 8.3$ \\
Ferritin (ng/mL) & $146.1 \pm 134.1$ \\
Serum Alb (g/dL) & $3.5 \pm 0.5$ \\
Intact PTH (pg/mL) & $263.6 \pm 170.9$ \\
CRP (mg/dL) & $0.28 \pm 0.38$ \\
BNP (pg/mL) & $165.1 \pm 454.7$ \\
Cardiothoracic ratio $(\%)$ & $49.5 \pm 5.41$ \\
Iron preparation use & $11.5 \%(3 / 26)$ \\
Use of RAS inhibitor $(\mathrm{ACE}$ inhibitor or & $73.1 \%(19 / 26)$ \\
ARB) & \\
\hline
\end{tabular}

Values expressed as means $\pm \mathrm{SD}$

$A D P K D$ Autosomal dominant polycystic kidney disease, FSGS Focal segmental glomerulosclerosis, $B U N$ blood urea nitrogen, $\mathrm{Cr}$ creatinine, $e G F R$ estimated glomerular filtration rate, $H b$ hemoglobin, TSAT transferrin saturation, Alb albumin, $P T H$ parathyroid hormone, $C R P$ C-reactive protein, $B N P$ brain (or B-type) natriuretic peptide, $R A S$ renin-angiotensin system, $A C E$ inhibitor angiotensin-converting enzyme inhibitor, $A R B$ angiotensin II receptor blocker

prior to PD initiation, $86.5 \mu \mathrm{g} / \mathrm{month}$ at PD initiation, and $72.0 \mu \mathrm{g} / \mathrm{month}$ at 4 weeks after initiation (Fig. 2). Thus, CERA dosage tended to increase immediately before PD initiation and then tended to decrease thereafter.

Figures $3 \mathrm{a}, \mathrm{b}$ show the changes in TSAT and ferritin levels. Throughout the observation period, average TSAT levels were maintained above $20 \%$, suggesting that iron levels were sufficient. Three of the enrolled patients received iron-replacement therapy; during the course, no significant differences in the iron-related data were observed between these patients and patients who did not receive iron replacement. Serum ferritin levels tended to be higher prior to PD initiation than after initiation. ERI, an indicator of hyporesponsiveness to ESA treatment, tended to increase as PD initiation approached, peaked at PD initiation, and tended to decrease after PD initiation (Fig. 3c). ERI gradually increased again over time after PD initiation. 
Fig. 2 Serial changes in $\mathrm{Hb}$ levels and CERA dosage from 24 weeks before through 24 weeks after PD initiation. Values are expressed as means \pm SD. Left axis: dosage of CERA ( $\mu \mathrm{g} / \mathrm{month})$, Right axis: $\mathrm{Hb}$ level $(\mathrm{g} / \mathrm{dL})$ ${ }^{*} P<0.05$ vs. week $0 . H b$ hemoglobin, CERA continuous erythropoietin receptor activator, $P D$ peritoneal dialysis

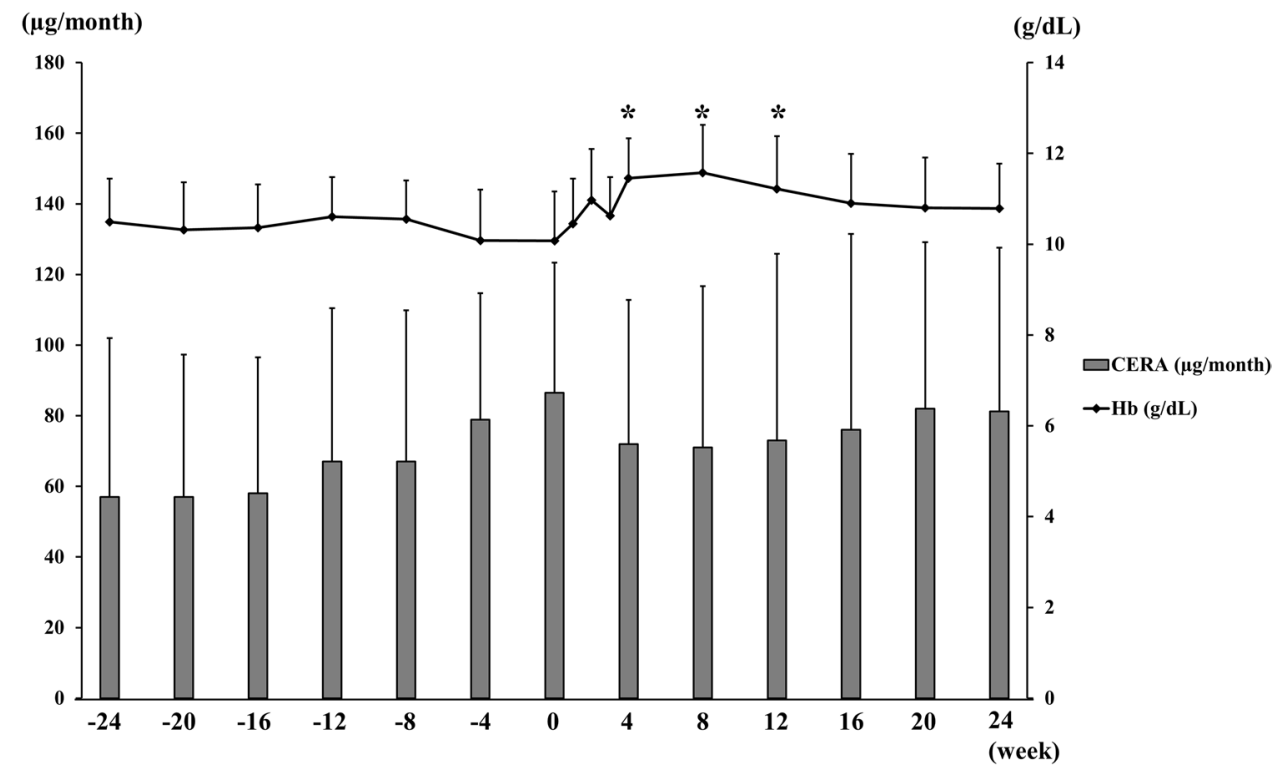

(a)

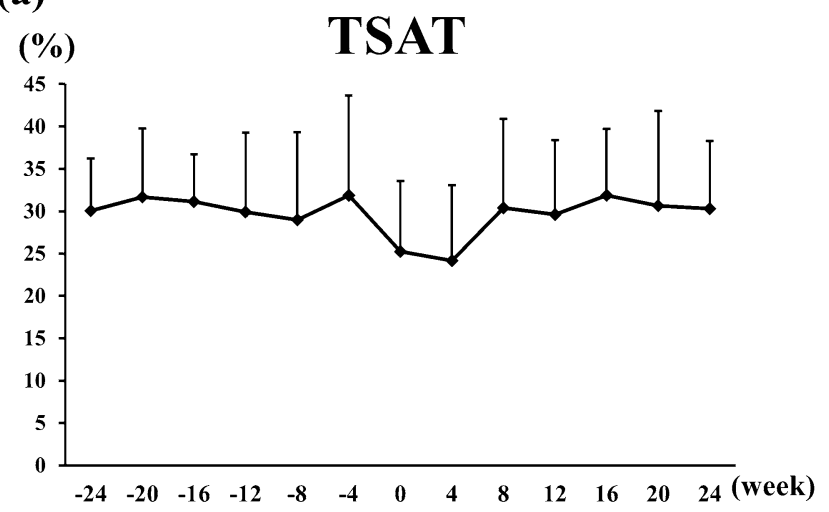

(c)

$(\mu \mathrm{g} / \mathrm{kg} / \mathrm{g} / \mathrm{dL} /$ week $)$

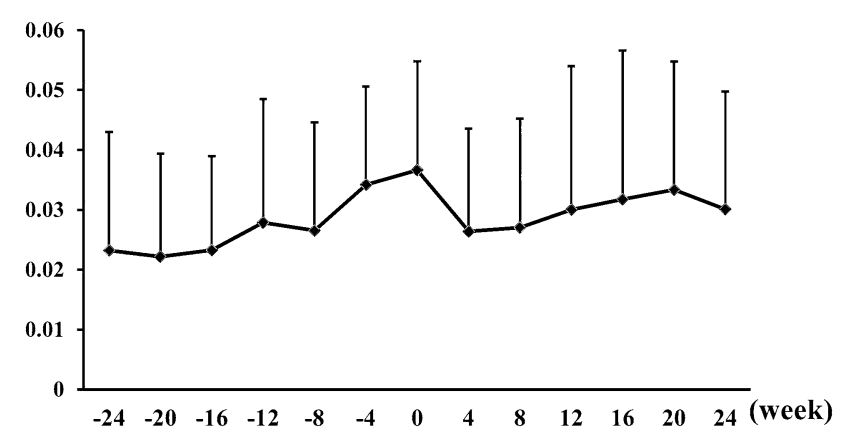

Fig. 3 Changes in TSAT (a), ferritin levels (b), and ESA resistance index (c) from 24 weeks before through 24 weeks after PD initiation. Values are expressed as means $\pm \mathrm{SD}$. TSAT transferrin saturation, $P D$ (b)

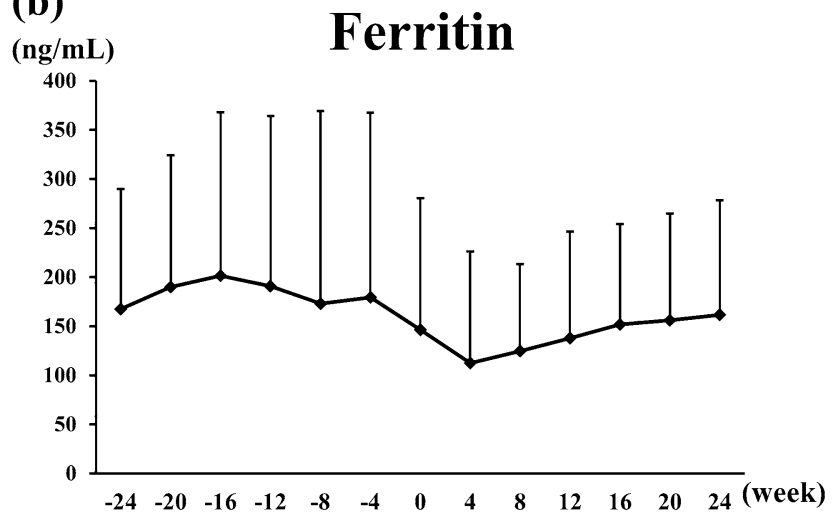

peritoneal dialysis, ESA erythropoiesis-stimulating agents, ERI erythropoietin resistance index. ERI is calculated as follows: $E R I=C E R A$ dosage $(\mu \mathrm{g} / \mathrm{month}) / \mathrm{BW}(\mathrm{kg}) / \mathrm{Hb}(\mathrm{g} / \mathrm{dL}) / 4$ weeks 
Table 2 The $2 \times 2$ tables showing the number of patients with Hb levels $\geq 11 \mathrm{~g} / \mathrm{dL}$ or $<11 \mathrm{~g} / \mathrm{dL}$ before and after PD initiation

(a) Comparison between -4 weeks vs. 4 weeks

\begin{tabular}{|c|c|c|c|c|}
\hline \multirow[t]{2}{*}{$-4 \mathrm{w}$ vs. $4 \mathrm{w}$} & & \multicolumn{2}{|c|}{ Week 4 (after initiation) } & \\
\hline & & $\mathrm{Hb} \geq 11$ & $\mathrm{Hb}<11$ & \\
\hline \multirow[t]{2}{*}{ Week - 4 (before) } & $\mathrm{Hb} \geq 11$ & 3 & 1 & McNemar's test \\
\hline & $\mathrm{Hb}<11$ & 14 & 7 & $P<0.05$ \\
\hline \multicolumn{5}{|c|}{ (b) Comparison between -4 weeks vs. 8 weeks } \\
\hline \multirow[t]{2}{*}{$-4 \mathrm{w}$ vs. $8 \mathrm{w}$} & & \multicolumn{2}{|c|}{ Week 8 (after initiation) } & \\
\hline & & $\mathrm{Hb} \geq 11$ & $\mathrm{Hb}<11$ & \\
\hline \multirow[t]{2}{*}{ Week - 4 (before) } & $\mathrm{Hb} \geq 11$ & 3 & 1 & McNemar's test \\
\hline & $\mathrm{Hb}<11$ & 16 & 5 & $P<0.05$ \\
\hline
\end{tabular}

$P$ values were calculated using statistical analysis of McNemar's test

$H b$ hemoglobin

Table 3 Comparison of the data at PD initiation between the patients without diabetes (Non-DM) and those with diabetes (DM)

\begin{tabular}{llll}
\hline & Non-DM & DM & $P$ value \\
\hline Patient number & 16 & 10 & \\
Age (years) & $63.4 \pm 9.8$ & $57.1 \pm 13.4$ & 0.12 (NS) \\
Sex & male/female $=7 / 9$ & male/female $=6 / 4$ & \\
Body weight (kg) & $59.3 \pm 8.6$ & $63.3 \pm 11.3$ & 0.18 (NS) \\
BUN (mg/dL) & $75.2 \pm 24.1$ & $73.9 \pm 26.7$ & 0.44 (NS) \\
Serum Cr (mg/dL) & $9.06 \pm 1.47$ & $10.13 \pm 2.29$ & $0.11(\mathrm{NS})$ \\
eGFR (mL/ & $4.63 \pm 1.16$ & $4.70 \pm 1.61$ & 0.45 (NS) \\
$\quad$ min/1.73 m²) & & & \\
Serum Alb (g/dL) & $3.51 \pm 0.37$ & $3.44 \pm 0.63$ & 0.37 (NS) \\
Intact PTH (pg/ & $300.7 \pm 185.7$ & $208.1 \pm 127.2$ & 0.08 (NS) \\
$\quad$ mL) & & & \\
CRP (mg/dL) & $0.34 \pm 0.43$ & $0.19 \pm 0.28$ & 0.33 (NS) \\
BNP (pg/mL) & $199.4 \pm 574.3$ & $110.3 \pm 70.6$ & 0.28 (NS) \\
HbA1c $(\%)$ & $5.6 \pm 0.4$ & $6.1 \pm 1.2$ & $0.12(\mathrm{NS})$ \\
\hline
\end{tabular}

Values are expressed as means \pm SD. $P$ values are calculated using Welch's $t$ test

$B U N$ serum blood urea nitrogen, $C r$ creatinine, $e G F R$ estimated glomerular filtration rate, $A l b$ albumin, $P T H$ parathyroid hormone, $C R P$ $\mathrm{C}$-reactive protein, $B N P$ brain (or B-type) natriuretic peptide, $N S$ not significant

We evaluated the changes in the number of patients with $\mathrm{Hb}$ levels exceeding the target value of $11 \mathrm{~g} / \mathrm{dL}$ before and after PD initiation. Table 2 shows the results analyzed by McNemar's test. After PD initiation (at weeks 4 and 8 after initiation), the number of patients with $\mathrm{Hb}$ levels above $11 \mathrm{~g} / \mathrm{dL}$ significantly increased, as compared to the number at 4 weeks before PD initiation.

Next, we compared the data of patients with and without diabetes (10 and 16 each) in order to examine whether diabetes affects the efficacy of CERA for anemia management. Table 3 shows the data of these patient groups at PD initiation. There were no significant differences between the two groups in terms of age, body weight, blood urea nitrogen, serum $\mathrm{Cr}$, serum albumin, iPTH, CRP, brain natriuretic peptide, or $\mathrm{HbA1c}$ at $\mathrm{PD}$ initiation.

Figure 4 shows the comparison of Hb levels (Fig. 4a), ERI (Fig. 4b), and CERA dosage (Fig. 4c) between the patients with and without diabetes at the time of PD initiation. The average $\mathrm{Hb}$ level of patients without diabetes was $10.6 \pm 0.8 \mathrm{~g} / \mathrm{dL}$, while that of patients with diabetes was $9.2 \pm 0.9 \mathrm{~g} / \mathrm{dL}$; the $\mathrm{Hb}$ level was significantly lower in the group with diabetes. The average ERI values were $0.033 \pm 0.016$ and $0.042 \pm 0.019$ in the groups without and with diabetes, respectively, and thus tended to be higher in patients with diabetes. The average CERA dosages were $79.7 \pm 35.6 \mu \mathrm{g} / \mathrm{month}$ and $97.2 \pm 38.1 \mu \mathrm{g} / \mathrm{month}$ in patients without and with diabetes, respectively, showing a trend for a higher dosage in those with diabetes.

Figure 5 shows the chronological changes in $\mathrm{Hb}$ levels (Fig. 5a), ERI (Fig. 5b), and CERA dosage (Fig. 5c) in the patients with and without diabetes throughout the evaluation period. $\mathrm{Hb}$ levels appeared to be higher in the group without diabetes during the period from pre- to post-PD initiation, while CERA dosage and ERI tended to be lower for most of this period. Of note, in the group without diabetes, CERA dosage significantly decreased after PD initiation (79.7-56.7 $\mu \mathrm{g}$ at 8 weeks), whereas no change was observed in the group with diabetes (97.2-102.8 $\mu \mathrm{g}$ at 8 weeks). There were no adverse reactions to CERA throughout the evaluation period. 

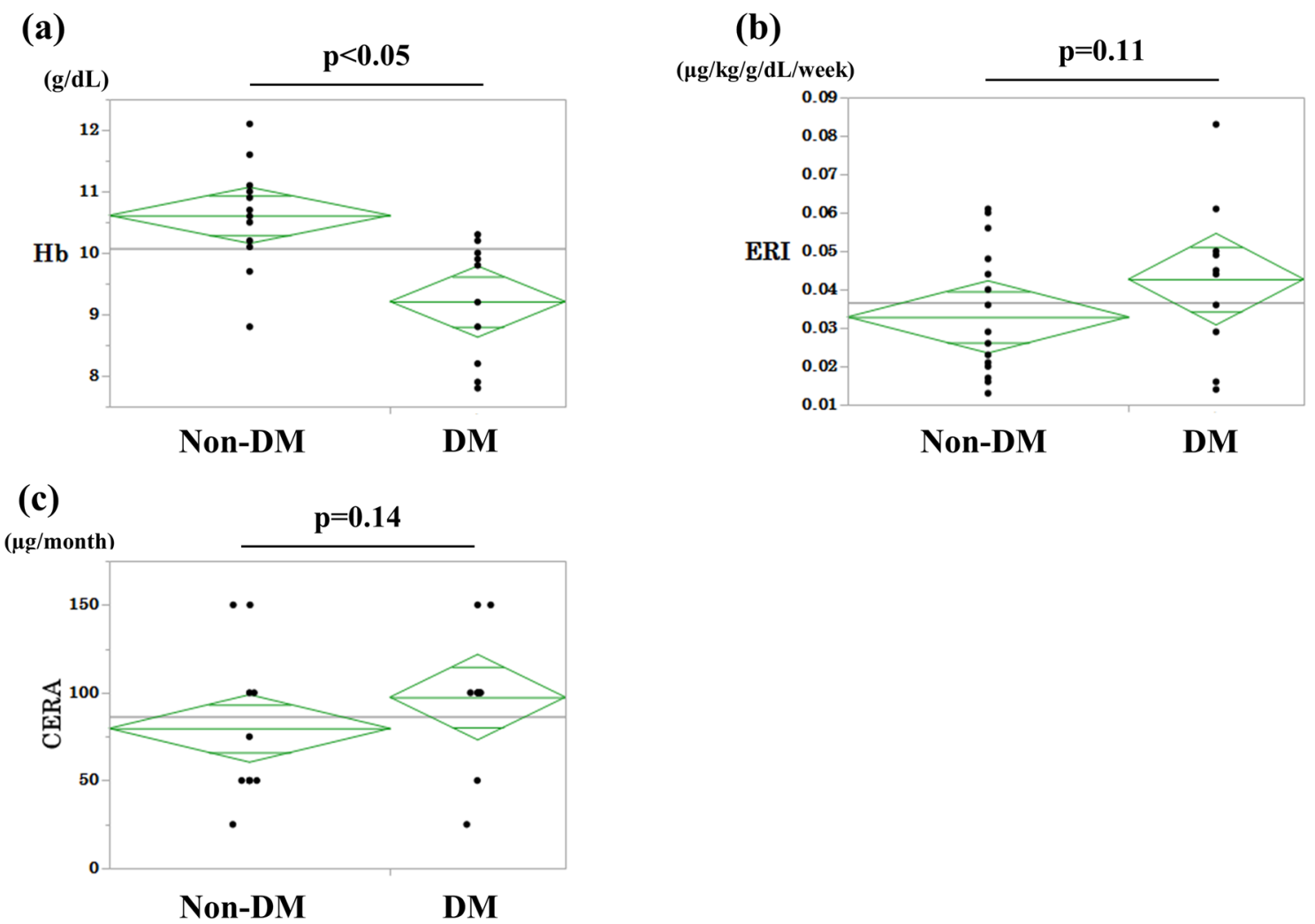

Fig. 4 Comparison of Hb levels (a), ERI (b), and CERA dosage (c) at PD initiation among patients with diabetes vs. patients without diabetes. $H b$ hemoglobin, CERA continuous erythropoietin receptor activator, $P D$ peritoneal dialysis, $E R I$ erythropoietin resistance index,

\section{Discussion}

In the care of patients with advanced CKD, there is an increasing awareness of the importance of the optimal transition from the pre-dialysis run-up to renal replacement therapy, including PD [19]. In particular, the adequate management of anemia is reported to be critical in the incident hemodialysis (HD) patients for preventing cardio- and cerebrovascular events during this period [20]. It has been proposed that treatment using CERA could achieve successful anemia control in patients on maintenance PD [21]; however, very few reports have examined anemia management by ESA throughout the period from pre- to post-PD initiation. We, therefore, assessed the effect of CERA treatment during the period from pre- to post-PD initiation and compared the efficacy of treatment in patients with and without diabetes.

In the present study, we showed that $\mathrm{Hb}$ levels tended to decrease as PD initiation approached, and then increased after PD initiation. This trend was also previously observed in HD patients [20]. Several studies have suggested that uremic toxins or uremia-induced inhibitors of erythropoiesis could contribute to the aggravation of renal anemia [22,

ESA erythropoiesis-stimulating agents, Non-DM non-diabetes, $D M$ diabetes. Analyses were performed using Welch's $t$ test. Patients with diabetes: $n=10$; patients without diabetes: $n=16$

23]. Our results suggested that mitigating uremic status by initiating dialysis could improve renal anemia without the reinforcement of ESA treatment. This notion was also consistent with the apparent decrease of ERI after PD initiation (Fig. 3). However, our study involved the periods from the last CERA administration just prior to PD initiation up to PD initiation and from PD initiation up to the next CERA administration, which varied across patients (without a 4-week interval). Therefore, the elevation of $\mathrm{Hb}$ levels might be partly due to the CERA dosage increase just before PD initiation.

Our data showed that $\mathrm{Hb}$ measurements returned to low levels at 24 weeks after PD initiation. We assumed that this finding was due to the decreased residual renal function. Data on residual renal function at 24 weeks after PD initiation were not available; however, we routinely evaluated daily urine volume, residual renal $\mathrm{Kt} / \mathrm{V}$ urea, and creatinine clearance (Ccr) at 1 year after PD initiation. As shown in Supplementary Fig. S1 and Supplementary Table S1, residual renal function significantly decreased after 1 year; therefore, we presumed that residual renal function decreased to a certain extent at 24 weeks after PD initiation. 
(a)

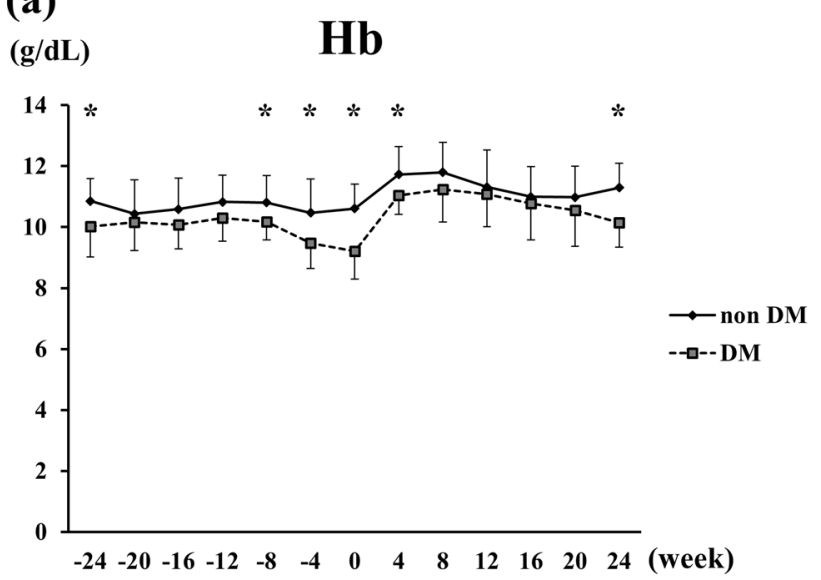

(c)

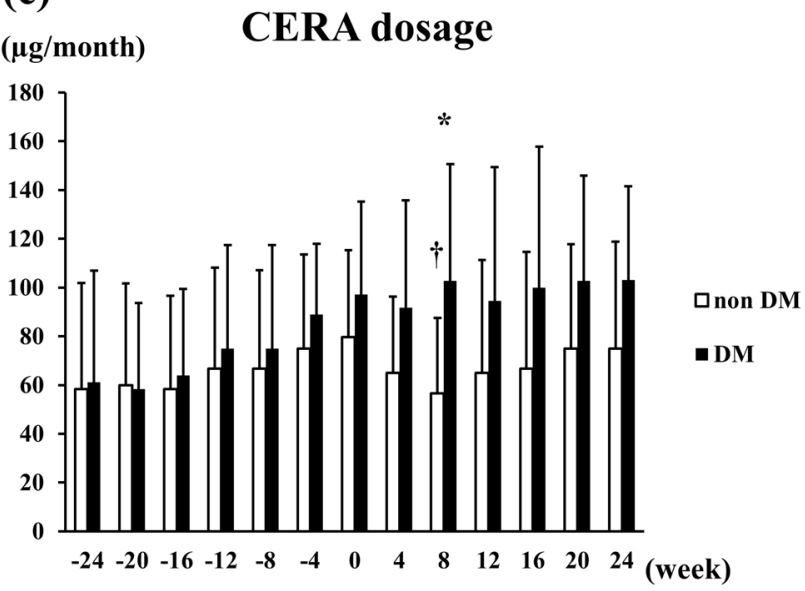

Fig. 5 Comparison of Hb levels (a), ERI (b), and CERA dosage (c) from 24 weeks before through 24 weeks after PD initiation between patients with and without diabetes. $H b$ hemoglobin, CERA continuous erythropoietin receptor activator, $P D$ peritoneal dialysis, ERI

The target $\mathrm{Hb}$ level for patients with CKD without dialysis and those undergoing PD is between $11 \mathrm{~g} / \mathrm{dL}$ to $13 \mathrm{~g} /$ $\mathrm{dL}$, according to the guidelines of the Japanese Society for Dialysis Therapy [9]. In this study, the average $\mathrm{Hb}$ levels did not fall below $10 \mathrm{~g} / \mathrm{dL}$ throughout the evaluation period. In the post-PD initiation period in particular, the percentage of patients with $\mathrm{Hb}$ levels above $11 \mathrm{~g} / \mathrm{dL}$ increased significantly. These results indicate that anemia treatment using CERA throughout the period from pre- to post-PD initiation is useful for maintaining the target $\mathrm{Hb}$ level. To our knowledge, assessment of renal anemia using CERA throughout the period from pre- to post-PD initiation has not been reported to date. However, during the period without dialysis, more than half of the CKD patients could not reach the target $\mathrm{Hb}$ level. We speculate that a portion of patients failed to receive an adequate ESA treatment before PD initiation, partly because of its cost and infrequent hospital visits during the non-dialysis period. In Japan, during this period, (b) $(\mu \mathrm{g} / \mathrm{kg} / \mathrm{g} / \mathrm{dL} /$ week $) \quad$ ERI

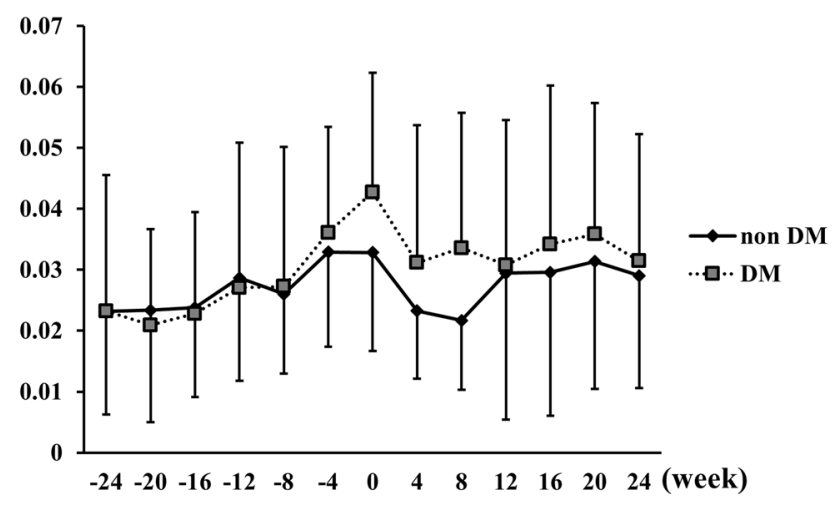

erythropoietin resistance index, ESA erythropoiesis-stimulating agents. Analyses were done by Welch's $t$ test. $*<0.05$ (DM vs. non$\mathrm{DM}), \dagger<0.05$ (week 8 vs. week 0)

patients have to pay 10-30\% of their medical expenses themselves; patients receiving dialysis can obtain more financial support than non-dialysis patients.

There were several notable differences between previous reports of HD patients receiving CERA treatment and the current study. The average CERA dosage tended to be less, and $\mathrm{Hb}$ levels tended to be higher in our patients than in those who started HD [24, 25]. PD is often initiated from an earlier stage of renal failure than is HD, because the residual renal function is critical for optimally performing and continuing PD therapy. Under such circumstances, interstitial damage is assumed to be milder, so that relatively high $\mathrm{Hb}$ levels can be maintained.

Patients with diabetic nephropathy were reported to develop renal anemia from an earlier stage of renal failure than did those with other causes of CKD [17]. To date, few reports have examined the association of diabetes with ESA treatment in patients receiving PD. In HD patients or 
non-dialysis CKD patients, several investigations have compared patients with and without diabetes [26-28]; however, the conclusions were controversial. In the present study, $\mathrm{Hb}$ levels were significantly lower in patients with diabetes, although other characteristics were not significantly different. CERA dosage and ERI tended to be higher in the group with diabetes. Moreover, in patients without diabetes, CERA dosage decreased significantly after PD initiation, whereas it remained unchanged in patients with diabetes. These results suggested that the presence of diabetes could have a negative influence on renal anemia management. Chronic inflammation has been reported to be involved in the progression of diabetic kidney disease, including tubulointerstitial lesions $[29,30]$, and this may be associated with deterioration of renal anemia and possible ESA hypo-responsiveness in patients with diabetes. Moreover, the residual renal function of diabetic patients tended to decline faster than that of non-diabetic patients (the decline of Ccr during 1 year after $\mathrm{PD}$ initiation was $32.8 \pm 14.7 \mathrm{~L} /$ week in diabetic patients and $21.1 \pm 24.5 \mathrm{~L} /$ week in non-diabetic patients, which was not significantly different), and two of 10 diabetic patients were forced to stop PD, while none of the non-diabetic patients stopped within 1 year after PD initiation. These differences may be associated with the higher dose of CERA and lower $\mathrm{Hb}$ levels in diabetic patients after PD initiation.

Other than diabetes, factors that may influence anemia are excess body fluid (and/or congestive heart failure) and RAS inhibition. The chronological change in BNP after PD initiation is shown in Supplementary Fig. S2. We had insufficient data for prior to PD initiation. The values varied widely, and no significant correlations with anemia parameters were observed. RAS inhibition is reported to be associated with renal anemia progression, because it may suppress erythropoietin production [31]. We evaluated the average $\mathrm{Hb}$ levels in patients with or without RAS inhibitor treatment. The average Hb levels were $10.1 \mathrm{~g} / \mathrm{dL}$ in patients with RAS inhibitors and $9.8 \mathrm{~g} / \mathrm{dL}$ in patients without RAS inhibitors, which was not significantly different.

There were several limitations to our study. First, the sample size was small; therefore, the statistical power was insufficient to detect any statistical significance in the correlation between two or more variables. Second, the observational period was only 48 weeks, and we could not evaluate the long-term outcomes and prognosis. Several studies have reported that ESA responsiveness is associated with long-term prognosis in HD patients or renal survival in CKD patients [32, 33]. Hence, follow-up of these PD patients for a more extended period could provide further insights.

In conclusion, CERA was shown to be effective for adequate anemia management, both before and after PD initiation. Moreover, the results suggested that the required dosage of CERA could be reduced in patients without diabetes after PD initiation, whereas the dose may remain unchanged in those with diabetes. Further investigation with a larger number of patients is warranted to validate this notion in the future.

Acknowledgments We are grateful to Dr. Koji Oba (Associate Professor of Department of Biostatistics, School of Public Health, Graduate School of Medicine, The University of Tokyo) for his helpful suggestions about statistical analysis. We greatly appreciate all the patients who participated in this study. None of the authors have any conflicts of interest to disclose.

\section{Compliance with ethical standards}

Conflicts of interest The authors have declared that no conflict of interest exists.

Research involving human participants and/or animals The study was conducted in accordance with the Declaration of Helsinki and was approved by the independent Ethics Committee of Kumamoto University (No. 1874).

Informed consent This study was a retrospective observational study without any interventions. We performed this study using an opt-out method of enrolment.

Open Access This article is licensed under a Creative Commons Attribution 4.0 International License, which permits use, sharing, adaptation, distribution and reproduction in any medium or format, as long as you give appropriate credit to the original author(s) and the source, provide a link to the Creative Commons licence, and indicate if changes were made. The images or other third party material in this article are included in the article's Creative Commons licence, unless indicated otherwise in a credit line to the material. If material is not included in the article's Creative Commons licence and your intended use is not permitted by statutory regulation or exceeds the permitted use, you will need to obtain permission directly from the copyright holder. To view a copy of this licence, visit http://creativecommons.org/licenses/by/4.0/.

\section{References}

1. NKF-K/DOQI Clinical practice guidelines for anemia of chronic kidney disease: update 2000. Am J Kidney Dis. 2001;37:S182-238.

2. Vlagopoulos PT, Tighiouart H, Weiner DE, et al. Anemia as a risk factor for cardiovascular disease and all-cause mortality in diabetes: the impact of chronic kidney disease. J Am Soc Nephrol. 2005;16:3403-10.

3. Weiner DE, Tighiouart H, Amin MG, et al. Chronic kidney disease as a risk factor for cardiovascular disease and all-cause mortality: a pooled analysis of community-based studies. J Am Soc Nephrol. 2004;15:1307-15.

4. Leaf DE, Goldfarb DS. Interpretation and review of healthrelated quality of life data in CKD patients receiving treatment for anemia. Kidney Int. 2009;75:15-24.

5. Kuriyama S, Tomonari H, Yoshida H, Hashimoto T, Kawaguchi Y, Sakai O. Reversal of anemia by erythropoietin therapy retards the progression of chronic renal failure, especially in nondiabetic patients. Nephron. 1997;77:176-85.

6. Jungers P, Choukroun G, Oualim Z, Robino C, Nguyen AT, Man NK. Beneficial influence of recombinant human erythropoietin 
therapy on the rate of progression of chronic renal failure in predialysis patients. Nephrol Dial Transplant. 2001;16:307-12.

7. Jones M, Ibels L, Schenkel B, Zagari M. Impact of epoetin alfa on clinical end points in patients with chronic renal failure: a meta-analysis. Kidney Int. 2004;65:757-67.

8. Levin A, Djurdjev O, Thompson C, et al. Canadian randomized trial of hemoglobin maintenance to prevent or delay left ventricular mass growth in patients with CKD. Am J Kidney Dis. 2005;46:799-811.

9. Yamamoto H, Nishi S, Tomo T, et al. 2015 Japanese society for dialysis therapy: guidelines for renal anemia in chronic kidney disease. Ren Replace Ther. 2017;3:36.

10. Locatelli F, Barany P, Covic A, et al. Kidney disease: improving global outcomes guidelines on anemia management in chronic kidney disease: a European renal best practice position statement. Nephrol Dial Transplant. 2013;28:1346-59.

11. Kdoqi. KDOQI Clinical practice guideline and clinical practice recommendations for anemia in chronic kidney disease: 2007. update of hemoglobin target. Am J Kidney Dis. 2007;2007(50):471-530.

12. Macdougall IC, Eckardt KU. Novel strategies for stimulating erythropoiesis and potential new treatments for anemia. Lancet. 2006;368:947-53.

13. Macdougall IC. CERA (Continuous Erythropoietin Receptor Activator): a new erythropoiesis-stimulating agent for the treatment of anemia. Curr Hematol Rep. 2005;4:436-40.

14. Macdougall IC, Robson R, Opatrna S, et al. Pharmacokinetics and pharmacodynamics of intravenous and subcutaneous continuous erythropoietin receptor activator (C.E.R.A.) in patients with chronic kidney disease. Clin J Am Soc Nephrol. 2006;1:1211-5.

15. Klinger M, Arias M, Vargemezis V, et al. Efficacy of intravenous methoxy polyethylene glycol-epoetin beta administered every 2 weeks compared with epoetin administered 3 times weekly in patients treated by hemodialysis or peritoneal dialysis: a randomized trial. Am J Kidney Dis. 2007;50:989-1000.

16. Koch M, Treiber W, Fliser D. Effective achievement of hemoglobin stability with once-monthly C.E.R.A. in peritoneal dialysis patients: a prospective study. Clin Drug Investig. 2013;33:699-706

17. Bosman DR, Winkler AS, Marsden JT, Macdougall IC, Watkins PJ. Anemia with erythropoietin deficiency occurs early in diabetic nephropathy. Diabetes Care. 2001;24:495-9.

18. Matsuo S, Imai E, Horio M, et al. Revised equations for estimated GFR from serum creatinine in Japan. Am J Kidney Dis. 2009;53:982-92.

19. Kalantar-Zadeh K, Kovesdy CP, Streja E, et al. Transition of care from pre-dialysis prelude to renal replacement therapy: the blueprints of emerging research in advanced chronic kidney disease. Nephrol Dial Transplant. 2017;32:ii91-ii98.

20. Kataoka H, Tsuchiya K, Naganuma T, et al. Relationship between anemia management at hemodialysis initiation and patient prognosis. Nephrology (Carlton). 2015;20(Suppl 4):14-211.
21. Gonzalez MT, Ramos R, Vera M, et al. Monthly CERA treatment maintains stable hemoglobin levels in routine clinical practice of peritoneal dialysis patients. Ren Fail. 2013;35:314-9.

22. Babitt JL, Lin HY. Mechanisms of anemia in CKD. J Am Soc Nephrol. 2012;23:1631-4.

23. Lee SW, Kim JM, Lim HJ, et al. Serum hepcidin may be a novel uremic toxin, which might be related to erythropoietin resistance. Sci Rep. 2017;7:4260.

24. Kawahara K, Minakuchi J, Yokota N, Suekane H, Tsuchida K, Kawashima S. Treatment of renal anemia with erythropoiesisstimulating agents in predialysis chronic kidney disease patients: Hemoglobin profile during the 6 months before initiation of dialysis. Nephrology. 2015;20(Suppl 4):29-322.

25. Yoshida T, Hayashi M. Anemia treatment by erythropoiesisstimulating agents during the 6 months before the initiation of hemodialysis: comparison of darbepoetin alfa and continuous erythropoietin receptor activator. Keio J Med. 2017;66:44-50.

26. Hirai T, Nishizawa Y, Nakazono H, et al. Hemoglobin maintenance and dosing strategies using intravenous continuous erythropoietin receptor activator in Japanese hemodialysis patients. Ther Apher Dial. 2013;17:498-503.

27. Ifudu O, Uribarri J, Rajwani I, et al. Gender modulates responsiveness to recombinant erythropoietin. Am J Kidney Dis. 2001;38:518-22.

28. Ishimura E, Nishizawa Y, Okuno S, et al. Diabetes mellitus increases the severity of anemia in non-dialyzed patients with renal failure. J Nephrol. 1998;11:83-6.

29. Lin M, Yiu WH, Wu HJ, et al. Toll-like receptor 4 promotes tubular inflammation in diabetic nephropathy. J Am Soc Nephrol. 2012;23:86-102.

30. Kuwabara T, Mori K, Mukoyama M, et al. macrophage-mediated glucolipotoxicity via myeloid-related protein 8/toll-like receptor 4 signaling in diabetic nephropathy. Clin Exp Nephrol. 2014;18:584-92.

31. Cheungpasitporn W, Thongprayoon C, Chiasakul T, et al. Reninangiotensin system inhibitors linked to anemia: a systematic review and meta-analysis. QJM. 2015;108:879-84.

32. Eriguchi R, Taniguchi M, Ninomiya T, et al. Hyporesponsiveness to erythropoiesis-stimulating agent as a prognostic factor in Japanese hemodialysis patients: the Q-Cohort study. J Nephrol. 2015;28:217-25.

33. Tsuruya K, Uemura Y, Hirakata H, et al. Association between responsiveness to methoxy polyethylene glycol-epoetin beta and renal survival in patients with non-dialysis-dependent chronic kidney disease: a pooled analysis of individual patient-level data from clinical trials. Nephrology. 2017;22:769-75.

Publisher's Note Springer Nature remains neutral with regard to jurisdictional claims in published maps and institutional affiliations. 